\title{
O TEATRO NAS INSTITUIÇÕES PÚBLICAS CONTEMPORÂNEAS
}

\section{ARTIGO ORIGINAL}

JUNIOR, Jorge Luiz Machado ${ }^{1}$

ESTEVES, Alejandra Luisa Magalhães ${ }^{2}$

JUNIOR, Jorge Luiz Machado. ESTEVES, Alejandra Luisa Magalhães. O Teatro nas Instituições Públicas contemporâneas. Revista Científica Multidisciplinar Núcleo do Conhecimento. Ano 05, Ed. 01, Vol. 01, pp. 58-86. Janeiro de 2020. ISSN: 2448-0959, Link de acesso: https://www.nucleodoconhecimento.com.br/administracao/teatro-nasinstituicoes-publicas

\section{RESUMO}

O direito e as artes cênicas têm andado juntos durante séculos. As tragédias gregas retratavam os casos apresentados nos tribunais demonstrando uma estreita ligação entre ambos. Com o passar dos anos, por muitas vezes as peças teatrais refletem as incoerências das decisões judiciais ou das leis aplicadas de forma injusta ou ineficaz. As artes cênicas são utilizadas para auxiliar o graduando em Direito a vivenciar as experiências da profissão através da simulação de tribunais, monitorias onde há a necessidade de encenação. Contudo ressalta-se que a intenção é preparar o aluno para as diversas situações que este possa vir a passar no exercício de suas atividades. Neste contexto, observam-se as instituições públicas e suas peculiaridades. Estas apresentam uma imagem desgastada frente aos problemas enfrentados atualmente, como, a corrupção e ineficiência gerencial que são

${ }^{1}$ Discente Bacharel em Administração Pública 7º período e Tecnólogo em Gestão Pública.

${ }^{2}$ Doutorado em Programa de Pós-Graduação em Sociologia e Antropologia. Mestrado em História Social. Especialização em História da África e do Negro no Brasil. Graduação em Historia. 
abordados de forma mais profunda na busca por eventuais soluções para a morosidade na prestação de serviços. Por fim, nota-se que há possibilidade de correlacionar o teatro e as instituições públicas para elucidar o papel de seus atores no gerenciamento dos serviços prestados.

Palavras-chaves: teatro, instituição pública, morosidade.

\section{INTRODUÇÃO}

O teatro e o Direito andam lado a lado em suas diversas áreas de atuação. Em alguns casos as artes cênicas podem auxiliar da desenvoltura dos alunos frente ao juiz para expor suas premissas.

O termo teatro tem fundamento etimológico grego théatron, que configura a arte onde um ator ou um grupo de atores representa uma história para uma plateia em determinado local.

O teatro é originário da Grécia Antiga, no século IV a.C. como resultado dos festivais para louvar o Deus da alegria e da fertilidade, Dionísio. As artes cênicas eram representadas apenas por homens com grandes máscaras, pois as mulheres não eram consideradas parte da sociedade. Também na Grécia surgiram duas vertentes do teatro a comédia e a tragédia.

Fazendo um breve paralelo sobre as organizações públicas e as artes cênicas podese referir ao filme "A Repartição do Tempo" onde o diretor Santiago Dellape retrata a verdade das instituições públicas brasileiras com poucos funcionários ou com atores coadjuvantes, conhecidos como "aspones". Apesar de não ser uma peça teatral, vale salientar a importância da obra por seu caráter atual e crítico.

O longa metragem se passa na década de 1980, em Brasília. A Repartição Pública responsável por registrar invenções e patentes apresenta morosidade na execução dos seus serviços, quando ocorre a chegada de uma máquina, com aspecto de relógio de ponto que possibilita uma viagem no tempo em busca de um melhor 
aproveitamento do serviço público, o qual é visto como negligente e desinteressado. Entretanto, faz-se necessário salientar que os entraves burocráticos inerentes ao sistema atrapalham a continuidade do espetáculo. As antigas peças teatrais trágicas apresentavam temas relacionados à justiça e as normas.

A partir das revoluções ocorridas na Europa nos séculos XVII e XIX e da emersão da burguesia as peças teatrais sofreram influências do momento histórico e apresentam um caráter mais individual perdendo sua natureza social.

As influências do movimento romântico trouxeram às peças o lema da Revolução Francesa: fraternidade, igualdade e liberdade. No século XX, o teatro torna-se ferramenta da sociedade para debate e crítica, sem grande atenção as alegorias dos cenários e figurinos, com o intento de esclarecer a realidade social.

Segundo Teixeira (2018) há evidências de que os teatros foram originados na Grécia Antiga à semelhança dos tribunais e também eram empregados para representar a organização judiciária, permitindo ao povo julgar seus criminosos através de suas encenações. Esclarece através das palavras de Jeniffer Wise, professora de história do teatro na Universidade de Victoria que ambos refletem a "democracia em ação" e proporcionam uma avaliação das normas jurídicas com as experiências concretas da sociedade.

Deste modo, o objetivo do presente artigo é propor uma reflexão no leitor acerca do assunto. As artes cênicas utilizadas desde sua origem até os dias atuais como ferramenta a críticas sociais e consciencialização política, visando também intervir no Direito para a elaboração e modificação das leis em prol da sociedade e no desenvolvimento dos servidores que representam as constates mutações das instituições públicas contemporâneas.

Atualmente, a arte é uma linguagem universal que persiste em apresentar os aspectos marcantes da sociedade. Interpretar promove o conhecimento de dinâmicas inovadoras e diferentes do cotidiano do intérprete. É imperioso salientar a articulação entre o teatro e as entidades públicas de modo a identificar e familiarizar conceitos e 
funções empregando de forma leve, porém, critica a ineficácia apresentada pelas mesmas.

\section{AS INSTITUIÇÕES PÚBLICAS}

As instituições eram concebidas, no antigo direito romano com o desígnio de desempenhar a vontade do fundador, concretizando seus objetivos. No baixo Império Romano, através da ideologia cristã que pregava a caridade surgiram as fundações originais. Em entendimento a teoria individualista na visão de Bobbio (1992), os homens são titulares dos direitos e os destinatários destes direitos, nas fundações, são aqueles para os quais ela foi originada.

Nos tempos medievais, as fundações agiam sob o amparo da Igreja e tinham caráter público o que foi reduzido com a origem das nações contemporâneas e relevância inerente ao direito civil.

O decreto-lei n.․ 200/67, instituiu que as fundações eram semelhantes às empresas públicas e incorporaram a Administração Pública Indireta. Outros decretos vieram posteriormente questionando o posicionamento das entidades públicas como parte da Administração Indireta.

O decreto-lei $n . \stackrel{0}{2.299 / 86}$, acrescentando o parágrafo $2^{\circ}$, enquadrou as instituições no rol da Administração Indireta àquelas geradas, na intenção de subordiná-las a ferramentas e diretrizes de fiscalização, controle e gerenciamento financeiro, além do plano de carreira estabelecido pela Lei ㄲo 5.645/70.com advento de alterações, mediante lei, as fundações passaram a apresentaram natureza jurídica majoritariamente pública porque não adotam várias leis civilistas. Nesta norma, as entidades ficaram subjugadas ao Código Civil somente em relação à forma de constituição.

A literalidade constitucional diferenciava fundações públicas e privadas. Com o advento da emenda constitucional n.. $19 / 98$, não empregou mais a expressão 
fundação pública as mudanças esclarecem que a Constituição não distingue, logo, as normas da Carta Magna abarcam todos os tipos de fundação.

Art. 5ํㅜ Para os fins desta lei considera-se:

IV - Fundação Pública - a entidade dotada de personalidade jurídica de direito privado, sem fins lucrativos, criada em virtude de autorização legislativa, para o desenvolvimento de atividades que não exijam execução por órgãos ou entidades de direito público, com autonomia administrativa, patrimônio próprio gerido pelos respectivos órgãos de direção, e funcionamento custeado por recursos da União e de outras fontes (BRASIL, 1988, p. 13)

As entidades de direito público são originadas por lei enquanto aquelas de direito privado são geradas através autorização legal, conforme pressupostos da legislação civil. Ambas, adquirindo direitos e obrigações em seu próprio nome. Segundo o STF na Ação Direta de Inconstitucionalidade 191/RS em que a relatora foi a Ministra Carmen Lúcia. As formas que as fundações foram criadas divergem as Pública, das fundações privadas em decorrência da titularidade e natureza dos serviços prestados (ADMIN, 2008).

No que tange as regras da administração, as entidades públicas da administração indireta cumprem as normas da administração pública adequada a sua personalidade, qual seja, pública ou privada. (CARVALHO FILHO, 2009).

Deste modo elucida o Art. 37 da Carta Magna:

Art. 37. A administração pública direta e indireta de qualquer dos Poderes da União, dos Estados, do Distrito Federal e dos Municípios obedecerá aos princípios de legalidade, impessoalidade, moralidade, publicidade e eficiência e, também, ao seguinte: 
XIX - somente por lei específica poderá ser criada autarquia e autorizada a instituição de empresa pública, de sociedade de economia mista e de fundação, cabendo à lei complementar, neste último caso, definir as áreas de sua atuação. (BRASIL, 1988, p. 36 -37).

Portanto, as organizações públicas podem ser compostas pelo poder público com o capital, total ou parcialmente público, fiscalizado pela gestão pública, com possibilidade de autoadministração dentro dos limites da norma.

O patrimônio das organizações públicas de direito público é denominado como bem público protegido por todos os privilégios, como a impenhorabilidade dos bens. Já os bens das instituições de direito privado não se encaixam como bens públicos.

As mudanças vivenciadas no âmbito do gerenciamento público no Brasil podem ser identificadas na busca pela revitalização das ações do Estado, diga-se, melhorias no desempenho dos serviços prestados, bem como a gênese de novas diretrizes no relacionamento com a sociedade (MOTTA, 2007). Entretanto, a implementação destas mudanças sofre com a manutenção de aspectos clássicos da administração pública. Como uma peça que está por longo tempo em cartaz com grande aceitação pelo público, onde os atores desejam mudar o roteiro, improvisar, mas o autor não permite.

Anteriormente, o regime jurídico adotado pelos funcionários destas fundações seria o mesmo, como declarava o art. 39 da CF, o qual instituía o regime jurídico único. Com o advento da EC n 19/98, este sistema foi eliminado e o regime de pessoal passou a ser o utilizado pela pessoa federativa estabelecida através da legislação. Ambas as entidades possuem responsabilidade objetiva, pois 0 art. $37, \S 6^{\circ}$ da Constituição elucida (BRASIL, 1988).

A cultura organizacional é um elemento relevante para o entendimento do desempenho das organizações, sobretudo após as intervenções. Esta proposta busca redefinir omissões e ações do Estado e alcançar mudanças significativas no gerenciamento das entidades públicas, segundo Silva e Fadul (2010). 
A crise pela qual passa o Estado e a credibilidade daqueles que administram diversas organizações públicas requereu uma reconstrução interna para assegurar a propriedade os contratos, além de auxiliar a coordenação econômica no mercado e reduzir as desigualdades sociais. O referido plano busca permitir que os gestores tomem decisões assertivas e que os serviços, direta ou indiretamente subordinados a ele, funcionem de forma mais eficaz.

A globalização tornou relevante a redefinição de suas tarefas. Anteriormente a incorporação mundial dos mercados e dos modos produtivos, os Estados tinham como uma de suas metas básicas salvaguardar as respectivas economias da concorrência internacional. Depois do processo de globalização, o Estado não pôde manter esta postura, mas adotar um sistema econômico interno forte e que a torne internacionalmente competitiva.

Soma-se a estes elementos o grande retrocesso social gerado pelo governo neoliberal, uma vez que estamos enfrentando o Estado Pós-Democrático, onde tudo se torna mercadoria e as decisões políticas são tomadas pela direção das grandes corporações transnacionais, mercados, dentre outros. Deste modo, as entidades públicas não exercem suas funções de forma abrangente se não agir nos limites dos anseios do neoliberalismo, o que demonstra o seu desprezo pelos processos de legitimação popular, bem como seu profundo envolvimento com o Capital financeiro.

A diferença entre um plano de reforma neoliberal e um plano social democrática está no objetivo. No primeiro busca-se retirar o Estado da economia, enquanto no segundo a intenção é aumentar a governança do Estado.

A compreensão da natureza da crise e da necessidade imprescindível de aplicar a reforma no Estado ocorreu de forma imprevista e controversa. O país sofreu um período de cristalização da renda per capita, entre 1979 até 1994, e uma profunda inflação.

O que ocasionou essa crise na economia foi a crise estatal, que persiste ate os dias atuais, apesar dos esforços por finalizá-la. A depressão iniciada em 1979 foi gerada

Disponível em: https://www.nucleodoconhecimento.com.br/administracao/teatro-nas-instituicoespublicas 
pela segunda crise do petróleo, a qual se identifica pela ausência de capacidade do Estado em estruturar o sistema econômico para integralizar o mercado. Esta crise define-se como uma resseção de várias frentes: fiscal, política, do método de interferência do Estado, da Administração Estatal. Com o advento do Plano Real, em 1994, os preços estabilizaram-se favorecendo a recuperação do crescimento econômico.

A instabilidade política apresentou três períodos, segundo Pereira (1996): uma crise do sistema militar; e uma crise moral, que resultou no impeachment de Collor; a instabilidade do método de intervenção, ampliada pela globalização econômica mundial, qualificou-se pelo enfraquecimento do modo protecionista de permuta de importações, o que se demonstrou na ausência de competitividade de uma grande parte das companhias brasileiras; aparentou no insucesso de aproximar o Brasil dos modelos socialdemocratas europeus.

A Constituição de 1988 levou a gestão administrativa ao patamar oposto: uma rigidez burocrática intensa. Os resultados são custos altos e qualidade reduzida da gestão administrativa brasileira.

Esta reforma visou implementar melhores condições para aplicar leis e políticas públicas e tornar mais hábeis as atividades exclusivas do Estado, através da mudança das autarquias em "agências autônomas", bem como modificar os serviços sociais competitivos em organizações sociais.

No Estado não houve novos concursos públicos, uma vez que foram apresentados cálculos onde existiam mais servidores inativos do que ativos (MOTTA, 2007). Enquanto isso, com recursos humanos reduzidos o Estado ficou a mercê da crise fiscal. De acordo com (BRASIL, PDRA, 1995, p.26) "A rigidez da estabilidade assegurada aos servidores públicos civil impede a adequação dos quadros de funcionários às reais necessidades do serviço, e dificulta a cobrança do trabalho".

O procedimento monetário da União é definido pela assimetria, pois no Brasil não há um sistema padronizado de remuneração. O planejamento da Reforma foi inspirado

Disponível em: https://www.nucleodoconhecimento.com.br/administracao/teatro-nas-instituicoespublicas 
na administração britânica e objetivou fundar um novo padrão de gerenciamento público, fundamentado na demanda por maior rapidez com foco nos resultados, no público e no controle social.

O acerto fiscal dar-se-á através: da exoneração de servidores excedentes, da delimitação do teto remuneratório dos funcionários, e da mudança do processo de aposentadorias, com o aumento tempo de serviço, e da idade mínima para aposentadoria, com tempo mínimo de serviço e valor proporcional à contribuição.

A modernização da gestão pública apresenta-se como consequência do plano de reforma que buscará fortalecer o centro estratégico do Estado e desconcentrar o gerenciamento público através da introdução de outros núcleos controlados por contratos de gestão. O referido Plano tenta revigorar a competência administrativa central e oferecer autonomia as agências e das organizações sociais. Para alcançar o triunfo com a introdução da Reforma é imperioso o comprometimento de todos os atores e diretores envolvidos em todos os âmbitos dentro de suas prerrogativas especificas.

Cabe refletir como tais ideias estão sendo aceitas e empregadas na rotina das organizações públicas. Como esclarece Motta (2007), a administração pública encontra-se correlacionada com a cultura célebre e tais reformas poderão não interromper esta ligação de modo imediato. Neste contexto, acrescenta ainda que o patrimonialismo e o personalismo persistem e norteiam as 0 as convenções de preservação das coalizões de poder e salvaguarda de objetivos de coletividades preferenciais.

Por meio da experiência em conjunto das equipes das organizações encontram-se conclusões para os problemas rotineiros da companhia, pois são padrões e opiniões compartilhados que estabelecem o modus operante. Estes padrões e opiniões compartilhados formam a cultura organizacional (MOTTA, VASCONCELOS, 2006).

A premência de produzir um conceito positivo passou a ser o principal fundamento das administrações que buscam alcançar a qualidade. Ao invés de aplicar

Disponível em: https://www.nucleodoconhecimento.com.br/administracao/teatro-nas-instituicoespublicas 
investimentos na reestruturação do aparato público governamental ou em projetos e serviços, desembolsa-se uma grande quantia de recursos para encobrir a realidade da corrupção, do sucateamento, do nepotismo. A ineficácia sustenta-os e encobre-os desde o inicios das entidades públicas brasileiras. (SCHAUN, 1986).

As atividades intrínsecas do Estado, diga-se, a prerrogativa de legislar e tributar, é efetuada e engloba a polícia, as forças militares, as entidades de fiscalização e regulamentação, e os órgãos incumbidos pela cessão de recursos.

Os serviços não peculiares, que o Estado exerce e/ou patrocina porque os julgam extremamente relevantes para os direitos humanos ou abrangem economias externas.

Por fim, em cada setor deve-se analisar qual o tipo de natureza e qual o tipo de gestão pública mais adequada.

A complexidade inerente às instituições e a Reforma é uma questão que necessita de uma análise de diversos pontos da História do país. Não é uma simples questão administrativa a degradação das entidades públicas e, para compreender este processo devem-se analisar três razões, quais sejam: a cultura brasileira; a corrupção inerente ao poder público e a inabilidade gerencial do aparato público do governo.

\subsection{FATORES DE DEGRADAÇÃO DAS INSTITUIÇÕES PÚBLICAS}

a. Cultura Brasileira

Nelson Werneck Sodré (1996) revela em sua obra "Síntese de História da Cultura Brasileira" que os primeiros cultos do país eram jesuítas. No ensino religioso os ensinamentos eram transmitidos com objetivo essencial da catequese. Após muitos anos seguindo este sistema, a Reforma Pombalina é gerada pela necessidade de proscrição dos jesuítas, o que não leva a elaboração de um novo método educacional e beneficia o declínio do ensino no Brasil. Os padres e capelães eram os únicos com 
conhecimentos, contudo sem fundamento pedagógico. O processo educacional era para poucos e a conclusão geralmente acontecia nos países europeus.

A cultura, segundo Sodré (1996), tinha por objetivo alcançar o diploma, não o conhecimento, e deliberava que seus alunos seriam pregadores, cultos e gênios e que, deste modo ambicionavam as profissões liberais e os empregos públicos. A cultura dos índios e negros foi constrita e estes não tinham permissão para aprender, fato que impediu seus avanços. Esta divergência entre a abstração política avançada e o atraso do ambiente, demonstrava o ponto de desorientação cultural inerente aos povos com antecedentes coloniais.

A consequência destes fatos foi um ensino fundamental medíocre, por parte do Estado, e um ensino médio relegado às organizações particulares, as quais apresentavam caráter financeiro e intangível às classes mais humildes da população. Em pleno século XXI, o Brasil apresenta uma taxa de analfabetismo de $7 \%$ entre pessoas de 15 anos ou mais segundo dados do IBGE (OLIVEIRA, 2018). Um índice ainda muito distante dos apresentados pelos países desenvolvidos e alguns em desenvolvimento, como é o caso da Coréia, que em 45 anos praticamente erradicou o analfabetismo e colocou 82\% dos jovens na universidade. (MAZILLI, 2011).

Nelson Sodré (1996) apresenta uma relevante análise sobre a interferência dos meios de comunicação no processo educacional da população:

Nosso povo [...] é ainda acusado pelo baixo nível; os exploradores, comerciais e ideológicos, dos meios de comunicação de massa seriam simples vítimas desse incorrigível mau-gosto popular; no fim de contas, estão apenas fornecendo o que lhes é imposto pelas exigências desse mau-gosto. Essa impostura atinge os limites do escárnio, quando se sabe que a verdade é muito outra: o público aceita e procura o melhor. (SODRÉ, 1996, p.79).

Diante desse panorama de ignorância, parece improvável que a população brasileira combata as deliberações do sistema, contudo as políticas públicas que visam

Disponível em: https://www.nucleodoconhecimento.com.br/administracao/teatro-nas-instituicoespublicas 
contribuir para o ingresso das classes menos favorecidas no ensino superior e as mudanças curriculares no ensino fundamental e médio ambicionam equilibrar a balança do conhecimento para todos.

Enquanto em outras épocas, a imprensa atuava como a consciência da população, agora o povo questiona e rebela-se contra a imprensa, quiçá pelo advento da internet, mas principalmente para o despertar do conhecimento.

\section{b. Corrupção}

A corrupção tem sido assunto corriqueiro em todos os meios de comunicação e é apresentado como um dos fatores que levam a deterioração da reputação das entidades públicas. Do mesmo modo, estudos sobre o assunto vêm se ampliando e, em sua maioria consideram-no uma questão moral. Bezerra (1995), em sua obra "Corrupção: um estudo sobre poder público e relações pessoais no Brasil" conceitua a corrupção como um "fenômeno de natureza estrutural, enraizado em nossa formação social, aos nossos hábitos e costumes".

As delações sobre corrupção têm se apresentado mais frequentes e são retratadas pela mídia como uma crise ética. Cabe, para solucionar a questão, estabelecer padrões morais mais rígidos e éticos (BEZERRA, 1995).

O autor associa a corrupção e as relações pessoais e redes. Segundo ele, laços de amizade, parentesco ou apadrinhamento são propulsores para justificar atos de corrupção.

Stukart (1988) salientava esta ligação entre os atos corruptos em face das relações sociais: "Sem dúvida privilégios e mordomias moralmente apócrifos são igualmente um meio de suborno". Bezerra (1995) complementa:

Não são enfim, fatos excepcionais, mas práticas rotineiras. É de se notar, inclusive, que uma rápida observação nas denúncias de corrupção nos últimos anos permite constatar que as condutas assim designadas não 
são exclusivas de um período, mas têm se reproduzido e atravessado distintos grupos políticos e governos (BEZERRA, 1995, p. 186).

O autor esclarece que a corrupção faz parte da cultura da população brasileira e que, mesmo aqueles contrários a estas práticas, ao alcançarem status, privilegiam as relações pessoais.

[...] lemos quase que diariamente nos jornais e revistas casos de corrupção, mas raramente lemos sobre o ressarcimento dos prejuízos e/ ou punição dos corruptos, dando a impressão de que sofremos uma síndrome de impunidade, levando alguns a concluir que realmente 'o crime compensa. (STUKART, 1988, p.52).

Estes atos estão sendo gradualmente mais expostos à sociedade e contribuem para a imagem de precariedade de todo o sistema governamental. Para modificar este quadro, faz-se imperiosa a atitude de toda a sociedade no confronto contra a corrupção. O constante esforço social e a condenação dos corruptores podem empregar mudanças importantes para reduzir ou mesmo erradicar a corrupção no país (STUKART, 1988).

O autor complementa: O Código de Ética, criado conforme a necessidade de sobrevivência de um grupo precisa de sanções e castigos, para que não seja apenas um amontoado de meras palavras vazias. A negligência na aplicação destas determinará o seu desaparecimento gradual. (STUKART, 1988).

Segundo dados recentes do Instituto da Transparência Internacional, o Brasil ficou na 96ํㅜ posição dos países menos corruptos do mundo, caindo 17 posições em relação ao estudo anterior. A maioria dos territórios considerados mais corruptos vive em um sistema político ditatorial ou apresenta conflitos religiosos e péssimas condições de vida da população. (EXAME, 2018) 
c. Inabilidade gerencial

Faz-se relevante organizar o Estado para abandonar os sistemas burocráticos do passado para que este possa instaurar métodos gerenciais que estabeleçam no comportamento do trabalho público conceitos imperiosos de qualidade, produtividade e responsabilidade dos funcionários, segundo relatam Pereira e Spink (1998, p. 2324).

Os cidadãos exigem do Estado muito mais do que o Estado pode oferecer. Nesse caso, a função de uma administração pública eficiente passa a ter valor estratégico, ao reduzir a lacuna que separa a demanda social e a satisfação dessa demanda. O objetivo é construir um Estado que responda às necessidades de seus cidadãos; um Estado democrático, no qual seja possível aos políticos fiscalizar o desempenho dos burocratas e estes sejam obrigados por lei a lhes prestar contas, e onde os eleitores possam fiscalizar o desempenho dos políticos e estes também sejam obrigados por lei a lhes prestar contas.

Os supramencionados autores declaram que a crise burocrática da gestão pública brasileira se originou no regime militar, em face do patrimonialismo que impediu a consolidação de uma burocracia profissional recrutando gestores através das empresas do Estado. A Carta Magna de 1988 menosprezou as novas diretrizes da administração pública.

Os constituintes e, mais amplamente, a sociedade brasileira, revelaram nesse momento uma incrível falta de capacidade de ver o novo. Perceberam apenas que a administração burocrática clássica, que começara a ser implantada no país nos anos 30, não havia sido plenamente instaurada. Viram que o Estado havia adotado estratégias descentralizadoras - as autarquias e as fundações públicas - que não se enquadravam no modelo burocrático-profissional clássico. Notaram que essa descentralização havia aberto espaço para o clientelismo, 
principalmente nos estados e municípios - clientelismo que se acentuara após a redemocratização. Não perceberam, porém, que as formas mais descentralizadas e flexíveis da administração, que o Decreto-lei $\mathrm{n}^{\circ}$ 200/1967 havia consagrado, eram uma resposta à necessidade de o Estado administrar com eficiência as empresas e os serviços sociais. $E$ decidiram completar a revolução burocrática antes de pensar nos princípios da moderna administração pública. Ao agirem assim, aparentemente seguiram uma lógica linear compatível com a ideia de que primeiro seria necessário completar a revolução mecânica para só depois participar da revolução eletrônica. (PEREIRA e SPINK, 1999, p.246).

Muitos estudiosos de ciências políticas definem a importância da adoção, pela máquina pública do Estado, da eficácia do setor privado e o emprego de conceitos como qualidade e agilidade no fornecimento dos seus serviços. Neste contexto, a ações vão desde a privatização de organizações públicas até a adoção de um método híbrido de administração, amparado por Ferlie et al (1999).

Segundo Ferlie et al (1999), o método híbrido sugerido não é confiável ou lógico, mas poderia operar observando dois elementos: a arrecadação tributária e o mercado privado.

Uma análise elaborada pelo Banco Interamericano de Desenvolvimento - BID demonstra o tempo, dinheiro e a produtividade desperdiçados em face da burocracia nos países da América Latina. A falta de investimentos prejudica o aumento da celeridade nos serviços públicos. Procedimentos online demoram $74 \%$ menos que os presenciais para serem concluídos e geram um custo menor, igualmente a digitalização de documentos, além de diminuírem a incidência de corrupção. "A média para um único procedimento é de 5,4 horas, mas algumas nações podem ter atendimentos que demoram mais de 11 horas".(BID, 2018, p.4) 
Os trâmites burocráticos são difíceis na região: eles são lentos, suscetíveis à corrupção e acabam por excluir as pessoas com menos recursos. Muitos deles ainda são presenciais e envolvem documentos em papel. Os cidadãos perdem tempo indo de guichê em guichê e, em muitos casos, acabam pagando propinas aos servidores. As empresas perdem horas produtivas e, com elas, parte de sua competitividade. $O$ Estado se perde em meio a procedimentos complexos e manuais e não consegue conectar as políticas públicas aos beneficiários pretendidos (BID, 2018, p.2 )

O gasto com o atendimento presencial custa até 40 vezes mais do que um atendimento informatizado ao governo. O Brasil é um dos países que emprega mais tecnologias inovadoras no setor público. Infelizmente, ainda não é o suficiente para alcançar União Européia, por exemplo, que tem $81 \%$ dos serviços informatizados. No que tange a qualidade, nos países latinos é muito aquém do esperado. Somente metade dos procedimentos são resolvidos em uma única interação com o órgão público e $25 \%$ deles requerem três interações ou mais, o que gera um grande custo na hora de acessar serviços básicos como educação, saúde, pagamento de impostos e obtenção de uma certidão de nascimento (FERRARI, 2018)

Neste contexto, o "Brasil exige em média 5,4 horas para solucionar trâmites burocráticos" (BID, 2018. p.4). Antagônicos a ideologia que o Estado deve operar como uma empresa privada na prestação de serviços encontram-se Osborne e Gaebler. Os autores ressaltam as divergências entre instituições públicas e privadas, o que vai de encontro à utilização de um único método de administrar.

O governo é democrático e aberto; por isso seus movimentos são mais lentos comparados aos das empresas, cujos administradores podem tomar decisões rápidas, a portas fechadas. A missão fundamental do governo é 'fazer o bem', não é 'fazer dinheiro. [...]. Essas diferenças levam a uma conclusão: não se pode governar como quem administra 
uma empresa, embora certamente haja muitas semelhanças entre as duas atividades. (OSBORNE e GAEBLER, 1994, p.22).

Os referidos autores estabelecem que qualquer instituição, pública ou privada, podem empreender ou ser burocrática. No Brasil, as entidades públicas são extremamente burocráticas, o que torna os procedimentos administrativos morosos, reduz a produtividade e aumenta a corrupção (LAHÓZ, 2003).

Em uma pesquisa realizada pelo Banco Mundial em 133 países sobre a burocracia governamental e seus efeitos na economia, esclarece que o tempo é um fator mais relevante que os custos. Segundo Rita Ramalho, diretora do Banco Mundial "O tempo perdido com burocracia custa mais ao Brasil que impostos. Uma simplificação do atual sistema tributário para facilitar a vida do contribuinte" (LIMA, 2017)

Num ranking ponderando, o Brasil é considerado um dos mais burocráticos, levando 80 dias para o avanço de todo o processo.

abrange a análise histórica do Estado moderno e argumenta:

Há uma modernização, não se pode negar, mas é uma modernização chamada de conservadora. É a que Getúlio Vargas fez, a que os militares também fizeram, uma modernização que vem de cima, onde o Estado é extremamente poderoso. No caso brasileiro atual, como a nível mundial, também, o que está em jogo é essa redefinição de Estado. É um Estado que precisa ser reconstruído paralelamente à construção sólida de uma sociedade. No caso específico do Brasil, o Estado precisa ser reconstruído, mas é evidente que precisamos urgentemente construir uma sociedade. Não querendo ser pessimista, isto não vai acontecer num passe de mágica, não aconteceu nem acontece em lugar nenhum do mundo; e é bom que não aconteça, porque se acontecer é um castelo de areia que vai ruir a qualquer momento. Mas é necessário que seja construída essa sociedade, embora leve algum tempo, não importa [...]. (PINHO, 2001p. 37) 
Caio Marini (2003) em sua obra "Gestão pública: o debate contemporâneo" versa sobre a sustentabilidade no modo de modernização administrativa estatal e elucida:

[...] o debate contemporâneo sobre [...] as questões de gestão pública parecem reafirmar alguns dos princípios básicos da agenda atual, tais como: a focalização no cidadão, a transparência, o controle social, a conscientização da responsabilidade fiscal, a orientação da gestão para resultados, a ética e a profissionalização do servidor público. O grande desafio é o de assegurar a irreversibilidade do processo de transformação a partir do fortalecimento das iniciativas bem sucedidas e do realinhamento que se fizer necessário para a incorporação dos temas emergentes. (MARINI, 2003, p.82).

Segundo Roesler (2017), as organizações públicas não estão funcionando, pois não atende as pretensões neoliberalistas. O Poder Executivo e o Congresso Nacional têm trabalhado juntos para tentar implementar reformas que favoreçam o Capital Financeiro sem atentar para os interesses e necessidades da população. Ainda segundo o magistrado, as reformas são um retrocesso em vários aspectos e complementa: "O horizonte legislativo é o de promover mais retrocessos sociais através de "reformas" que atentam contra a dignidade do cidadão brasileiro."(ROESLER, 2017).

A ótica neoliberal determina que tudo pode ser privatizado, o que vem ocorrendo com diversas empresas públicas e o patrimônio do país. Em face do Pode Judiciário, o magistrado relata a indecisão dos juízes na atualidade que aplicam uma "justiça alternativa" em detrimento a Constituição Federal e o Ministério Público age de forma seletiva sob o pretexto de combater a corrupção e resguardar a segurança pública (ROESLER, 2017)

Nota-se, em síntese, que a degradação da imagem das organizações públicas não é um problema atual, mas, que persiste e aumenta em face das políticas governamentais de benefícios. Esta metodologia tem concretizado uma reputação 
negativa de governos e governantes. Tal panorama prejudica os homens sérios e honestos que ingressam na política com o intuito de modificar a situação de forma gradual. Encontra-se aqui a deseducação da população, a qual não consegue diferenciar ético do antiético.

\section{O TEATRO E O DIREITO}

Considera-se o teatro como uma espécie artística, e a arte como um movimento autossuficiente, relacionado ao prazer, e a reflexão. A tragédia, desde o início dos tempos, tem o caráter de ritual cívico como um encontro social que denotava a vida pública da pólis ateniense no século $\mathrm{V}$.

Em face de uma análise seletiva e focada na compreensão é possível apontar alguns meios de correlação, a vivência jurídica dos tribunais atenienses. Faz-se necessário reaver duas categorias: os processos elaborados e os assuntos inseridos nas peças. No que tange aos processos, há uma analogia entre os meios encontrados para garantir a atuação das tragédias e as ações procedimentais dos tribunais atenienses.

Segundo Roland Barthes (1990), é essencial sublinhar drasticamente o carácter civil do teatro grego, acima de tudo da tragédia, uma vez que foi a cidade que the forneceu a sua essência. A descrição da tragédia como suplemento da dinâmica da pólis ocorre, de acordo com Barthes (1990).

As tragédias todas eram comemorações para louvar o deus Dionísio e o teatro era destinado ao culto. Para decidir qual grupo apresentaria a tragédia nos festejos era feito um concurso, onde o arconde, oficial da pólis, ficava encarregado por preparar atores em frente a um grupo de jurados que decidiam, após a encenação quem atuaria na homenagem.

A coregia era um patrocínio atribuído pelos cidadãos ricos para a montagem das tragédias. Após a decisão do concurso o arconde, designava coregos. Complementa (BARTHES, 1990, p.71) "Os encargos financeiros eram pesados: cabia ao corego 
alugar a sala de ensaios, pagar pelo equipamento, fornecer bebida aos executantes, pagar a remuneração diária dos artistas".

O théôricon era um tipo de apoio prestado pela pólis. As apresentações eram originalmente gratuitas, porém, o número de espectadores aumentou gradualmente. Neste contexto, começaram a ser cobrados dois óbolos por dia de espetáculo Barthes (1990). Todos estes procedimentos para escolher, patrocinar e assistir a peça representa o controle direto da pólis mediante suas organizações e representantes.

Verificam-se, em paralelo, algumas condutas adotadas pelos tribunais atenienses, no século V, para solucionar as demandas. A cidadania era estendida somente aos homens adultos livres nascidos na cidade em famílias atenienses determinando que crianças, mulheres, estrangeiros e escravos estavam automaticamente exclusos. Observa-se que os tribunais eram exclusivos de cidadãos atenienses. Igualmente, a regra cabia às peças trágicas: os poetas e atores eram cidadãos atenienses.

Vários elementos empregados no concurso de tragédias encontram procedimentos correspondentes nos tribunais. Heliéia, o principal tribunal ateniense, tal como nos concursos, era composto por dez cidadãos de Atenas, com mandato anual, num procedimento conduzido pela assembleia e preparados para julgamento por um dos arcontes. (FINLEY,1991)

Os julgamentos eram públicos e realizados em espaço aberto com apresentações orais de ambas as partes, sem advogados ou promotores e a decisão cabia aos cidadãos presentes. (LOPES, 2000)

Quando as instituições políticas atenienses começaram a centralizar as discussões essenciais e assuntos relativos ao futuro da pólis, os cidadãos começaram a se preocupar com a aristocracia, cidadãos ricos que poderiam frequentar diariamente as entidades públicas sem prejudicar sua remuneração. Para universalizar a participação do povo, Atenas tomou medidas como a mistoforia, a qual era semelhante ao théôricon: pagava-se a diária do trabalho aos cidadãos para comparecer às sessões dos órgãos públicos.

Disponível em: https://www.nucleodoconhecimento.com.br/administracao/teatro-nas-instituicoespublicas 
Controlados pela cidade e exercidos em locais públicos (SEGAL, 1994). Ambos eram preparados por magistrados da pólis, careciam de sorteio para compor o corpo de jurados, eram exclusivos dos cidadãos, além do pagamento para o comparecimento das classes menos favorecidas, conforme determina Vernant e Vidal-Naquet (1999).

No conceito de Barthes (1990), a finalidade do agon é mediar os conflitos de modo imparcial. Por intermédio da tragédia a própria cidade se questiona sobre os valores cívicos e anticívicos. (VERNANT E VIDAL-NAQUET, 1999)

Do mesmo modo, a tragédia discute dilemas em torno da deliberação, segundo De Giorgi (2006).Tais dilemas são apresentados ao público e resolvidos em cena, enquanto a cidade enfrenta deliberações a todo o momento. A tragédia proporciona um questionamento sobre sua própria identidade, em face das contendas, impasses e laços. O referido autor complementa: "Os mitos apresentados na tragédia não refletem já os valores tradicionais de uma época remota, idealizada. Pelo contrário, tornam-se o campo de batalha das lutas internas da cidade" (SEGAL, 1994, p. 195).

Cabe salientar que no cerne da trama gira entorno da deliberação. Filósofos como Goethe, Hegel e Lacan resgataram a desavença da dúvida. (ROSENFIELD, 2006). O exame da peça abarca diversos dilemas como: a rivalidade entre a lei dos deuses, e a lei dos homens, apoiada por Creonte; a separação entre a civilização, e a natureza; o conflito político, para impedir a continuação do reino da dinastia dos cadmeus. (ALMEIDA, 1997). A referida peça apresenta um momento de transformação da própria religiosidade grega e da reminiscência das narrativas mitológicas, favorecendo um governo baseado nos critérios e na lógica humanas.

Ela emprega narrativas míticas como ferramenta para exteriorizar questões essenciais da política e do direito. As entidades primordiais da pólis democrática, segundo Rosenfield (2006).

O ensino do direito está cheio de hábitos e prosápias, como o trote, a monitoria, a simulação do tribunal do júri, dentre outros. O limite entre o direito e o teatro encontrase na encenação. Enquanto o teatro expõe assuntos do Direito, principalmente

Disponível em: https://www.nucleodoconhecimento.com.br/administracao/teatro-nas-instituicoespublicas 
voltados para os direitos humanos, as técnicas das artes cênicas são ferramentas pedagógicas para auxiliar na desenvoltura do futuro bacharel em Direito.

$\mathrm{Na}$ área de direito penal, é quando o bacharel mais reconhece o teatro, pois há a simulação de julgamentos como dos Tribunais do Júri, para exercitar as técnicas de retorica jurídica, que engloba a oratória, entonação, expressão facial e movimentação no espaço, quais se assemelham com as técnicas de encenação teatral.

O roteiro escrito pelo ator Thiago Scalia em conjunto com o juiz Henrique Macedo de Oliveira, em 2002, remete a época ditatorial comandado por Getúlio Vargas, entre 1930 e 1945. A peça buscou focar na violação dos direitos humanos.

Presidida por Kátia Bizzinoto, em 2014, foi originada a Comissão de Cultura, atriz e diretora de Teatro, com o objetivo de ampliar os esforços para firmar os direitos culturais entre os direitos fundamentais brasileiros, mediante as seguintes diretrizes: contribuição para formar cidadania cultural; promover atividades voltadas para temas culturais; cooperar e influenciar os projetos de leis com fins culturais e viabilizar intercâmbios entre a Arte e o Direito.

No Rio de Janeiro, a instituição de federal ensino, através de incentivos e parcerias possui o programa Jurisdrama que visa conscientização e defesa dos direitos individuais e coletivos, uma ação que, através de cursos e representações teatrais, abarca a reflexão interdisciplinar sobre assuntos jurídicos, sociais e econômicos, atendendo aos requisitos da extensão universitária, baseando-se no ensino e na pesquisa.

\section{CONCLUSÃO}

O Direito e o Teatro andam em paralelo desde o século V, quando as homenagens ao Deus Dionísio, deus da alegria, da fertilidade e da dissimulação era louvado com cânticos e encenações. Tais representações transpareciam o caráter de julgamento empregado nos tribunais através de suas histórias, permitindo que o povo expressasse sua opinião sobre assuntos da comunidade.

Disponível em: https://www.nucleodoconhecimento.com.br/administracao/teatro-nas-instituicoespublicas 
Havia concursos para a escolha dos grupos que se apresentariam nos festejos, bem como do conselho que julgaria uma determinada demanda. Dentre outras características, o teatro representava o caráter social de certas situações analisando as leis como justas ou injustas e observando os direitos humanos. Atualmente, o ensino de algumas técnicas das artes cênicas é introduzido em instituição de ensino superior aumentando, assim a vivência do aluno em sua futura profissão permitindo a sua atuação em simulações do tribunal do júri, por exemplo, além de outras ações que, através do teatro buscar elucidar questões jurídicas, Abrangendo a análise, há o filme "A repartição do Tempo", filme que retrata a realidade de muitas repartições públicas.

A crise pela qual passa o Estado e a credibilidade daqueles que administram diversas organizações públicas requereu uma reconstrução interna para assegurar a propriedade os contratos, além de auxiliar a coordenação econômica no mercado e reduzir as desigualdades sociais.

A partir daqui analisou-se as entidades públicas, como foco nas fundações e procurouse examinar o Plano de Reforma do Estado, instaurado em 1995. A gestão Pública brasileira vem sofrendo grandes transformações ao longo da última década buscando maior eficácia dos serviços públicos. A abordagem do Plano de Reforma pretende tornar a máquina estatal mais célere, flexível e pronta para atender as necessidades sociais com uma interpelação gerencial. A função principal do referido plano é apresentar princípios basilares para que os objetivos de ampliar a governança do Estado restringir a ação do Estado àquelas funções que lhe são próprias deslocar da União para os municípios as atividades de caráter local, e transladar parcialmente da União para os Estados as atividades de caráter regional possam ser plenamente estabelecidos.

A reforma do setor público em busca da qualidade na prestação de serviços propôs a descentralização das algumas organizações públicas e para implementar esta desconcentração foram necessárias mudanças na execução das atividades realizadas pelos servidores públicos. Dentre as diretrizes que nortearam os fins 
determinados pela reforma encontra-se a reorganização das entidades públicas e uma mudança das normas. Esta proposta busca redefinir omissões e ações do Estado e alcançar mudanças significativas no gerenciamento das entidades públicas, segundo Silva e Fadul (2010).

A crise pela qual passa o Estado e a credibilidade daqueles que administram diversas organizações públicas requereu uma reconstrução interna para assegurar a propriedade os contratos, além de auxiliar a coordenação econômica no mercado e reduzir as desigualdades sociais. A globalização tornou relevante a redefinição dos serviços públicos. Interiormente a incorporação mundial dos mercados e dos modos produtivos, os Estados tinham como uma de suas metas básicas salvaguardar as respectivas economias da concorrência internacional. Depois do processo de globalização, Estado não pôde manter esta postura, mas adotar um sistema econômico interno forte e que a torne internacionalmente competitiva.

Primeira reforma administrativa, baseada no fundamento do mérito profissional. A gestão pública burocrática foi instaurada para substituir o gerenciamento patrimonialista, que caracterizou as monarquias absolutas, que não diferenciava o limite. Nesse modelo de administração, o Estado era propriedade do rei, bem como o nepotismo e a corrupção era comum.

Esse tipo de gestão é antagônico, é imperioso para o capitalismo separar o Estado e o mercado e a democracia só existe quando a sociedade civil se diferencia do Estado e, paralelamente, o controla. Fez-se necessário desenvolver um molde administrativo imparcial, neste contexto surge à gestão burocrática moderna.

Gradualmente, foram-se projetando as bases da nova administração pública quais sejam a descentralização política, com transferência de recursos e prerrogativas para os âmbitos políticos regionais e locais; descentralização administrativa, através da cessão de autoridade para os gestores públicos transformados em gerentes autônomos; entidades com hierarquias menores; presumindo uma confiança limitada; e avaliação por resultados. 
A reforma instituída pelo Decreto Lei $200 / 67$ foi esforço para ultrapassar a rigidez burocrática, e pode ser considerada como a primeira gestão gerencial no Brasil. O cerne visava à descentralização em face da autonomia da gestão indireta. Estabeleceram-se como fundamento de racionalidade administrativa a organização, orçamento, a desconcentração e a avaliação dos resultados.

Nas bases descentralizadas foram utilizados funcionários celetistas, subordinados ao sistema privado de contratação. O período favorecia a expansão das companhias públicas. A flexibilidade de sua gestão buscava-se uma maior eficácia das práticas econômicas do Estado, e o fortalecimento do pacto político entre a burocracia tecnológica estatal, civil e militar, e o ramo empresarial.

O referido decreto teve dois resultados inesperados. Ao consentir a contratação de funcionários sem concurso público, facilitou a manutenção de práticas patrimonialistas e não realizou concursos ou planos de carreira. O centro estratégico do Estado foi desgastado, privilegiou a contratação dos altos escalões da gestão através das empresas estatais. A tentativa de reforma criada pelo Decreto lei 200 fracassou. $\mathrm{Na}$ década de 1970, a crise do regime militar agrava ainda mais o panorama da gestão pública, ao passo em que a burocracia estatal é reconhecida com o modelo autoritário em processo de degeneração.

A transição democrática ocorrida em 1985 não apresentou um horizonte favorável às reformas da máquina estatal. Pelo contrário, significou no âmbito administrativo uma volta às ideologias burocráticas anteriores, enquanto no âmbito político, representou um retorno ao populismo. No início do regime democrático, o a crise fiscal e a intervenção econômica foram desconsideradas, o sistema de trocas de importações foi mantido e os salários e os gastos públicos aumentaram, fatores que levaram ao fracasso do Plano Cruzado. Posteriormente, houve a tentativa de ajuste fiscal que foi frustrado pela falta de amparo da sociedade brasileira. Paralelamente a coalizão político-conservadora no Congresso instaurava uma política populista e patrimonialista. 
A Constituição de 1988 foi consequência destes movimentos contraditórios. A Carta Magna é uma resposta ao populismo que retrocede com a democracia, além de concretizar os fundamentos de uma gestão pública arcaica e burocrática com uma gestão pública centralizada, hierárquica e inflexível. A sociedade e os constituintes apresentaram falta de capacidade para inovar, uma vez que não notaram os modelos descentralizados e flexíveis consagrados pelo Decreto-Lei 200 como consequência de uma gestão estatal eficiente.

O retrocesso burocrático instaurado pela Constituição de 1988 foi uma atitude de resistência ao clientelismo que assolou o país naquele período, mas também ratificou os privilégios corporativistas e patrimonialistas contrários ao ethos burocrático. Tais elementos favoreceram a degradação da gestão pública do Brasil, embora a competência e honestidade dos administradores públicos brasileiros sejam notórias.

A instabilidade fiscal e do modelo intervencionista originaram-se a partir de 1987. Apenas com a hiperinflação durante o mandato de José Sarney a sociedade percebeu a gravidade da crise, contundo medidas, na tratativa de equalizar a Economia ganharam a atenção do governo de Fernando Collor, neste período conturbado ocorre à abertura comercial, com impulso da privatização. Os ajustes fiscais ganham diretrizes permanentes e o país alcança um amplo cancelamento da dívida pública interna.

No âmbito da gestão pública, as reformas tomaram um rumo diverso. Tal insucesso deveu-se, essencialmente, à tentativa desastrada de reduzir a máquina do Estado, exonerando funcionários e fechando órgãos, sem reocupação com a legalidade das medidas. Houve redução salarial dos servidores e desorganização da estrutura burocrática existente, desprestigiando os servidores públicos, reconhecidos pelo corporativismo (proteção dos interesses em um grupo como se representassem os interesses da nação).

O governo Itamar, (pós-impeachment), com a difícil missão, diante um cenário, de Recessão, descredito, falta de confiança no Governo, (interna e externa), sofrendo as 
consequências, da Gestão ineficaz. Em seu primeiro ano contou com a capacidade técnica da equipe econômica do Ministério da Fazenda da época, juntamente com a vontade de reequilibrar as contas públicas e a confianças do mercado e pessoas. Iniciam-se assim ações pautadas em estudos científicos, provocou a origem da carreira dos gestores públicos, os quais eram especializados em Políticas Públicas e Gestão Governamental.

O serviço público tornou-se mais ineficaz, mais custoso e autônomo. A cisão foi preparada não somente pelo modelo patrimonialista, mas igualmente pela imposição de um sistema jurídico unificado, com a exoneração dos celetistas e pela asserção constitucional de um modelo de estabilidade rígido, onde era inviável a avaliação de desempenho dos servidores Esta estabilidade do funcionalismo público é um aspecto inerente às gestões burocráticas e foi instaurada com o intuito de proteger os servidores e o próprio Estado. No Brasil, durante o período imperial, quando um governo era deposto, muitos funcionários de confiança, além de outros comuns perdiam seus cargos.

A estabilidade, contudo, tem um custo, impedindo a adaptação do quadro de servidores às verdadeiras necessidades do serviço. Em contrapartida, impossibilitava a introdução de um regime de gestão pública eficaz, fundamentado em um modelo de incentivos e punições.

Três fatores relevantes foram abordados que influenciam na degradação da imagem das instituições públicas quais sejam a corrupção, a cultura brasileira e a ineficiência gerencial.

A educação brasileira sempre foi precária, haja vista que objetivava o diploma e não o conhecimento. A cultura dos índios e negros foi constrita e estes não tinham permissão para aprender, esta divergência entre a abstração política avançada e o atraso do ambiente, demonstrava o ponto de desorientação cultural inerente aos povos com antecedentes coloniais. 
Em pleno século XXI, o Brasil apresenta uma taxa de analfabetismo de $7 \%$ entre pessoas de 15 anos ou mais segundo dados do IBGE (OLIVEIRA, 2018). Um índice ainda muito distante dos apresentados pelos países desenvolvidos e alguns em desenvolvimento. O panorama de deseducação da população brasileira impede maior interferência nas deliberações do sistema, entretanto a sociedade desperta gradualmente, talvez pelo advento da internet ou pelo cansaço frente ao desequilibro educacional.

A corrupção é um dos assuntos mais comentados atualmente e é considerada por estudiosos uma questão moral e ética. Bezerra (1995) conceitua a corrupção como um "fenômeno de natureza estrutural, enraizado em nossa formação social, aos nossos hábitos e costumes". Segundo o referido autor, para solucionar a questão, deve-se estabelecer padrões morais mais rígidos e éticos. Do ponto de vista sociológico é imperioso examinar que ao se beneficiar dos princípios morais como fundamento para este fenômeno, abandonam-se os debates sobre as condições sociais que auxiliam para a subsistência e renovação da corrupção no país. (BEZERRA, 1995). Para alterar este painel, a ação de toda a sociedade no confronto contra a corrupção é muito relevante. O constante esforço social e a condenação dos corruptores podem empregar mudanças importantes para reduzir ou mesmo erradicar a corrupção no país (STUKART, 1988).

Quanto à ineficiência gerencial cabe ressaltar que os métodos gerenciais devem estabelecer valores importantes como qualidade produtividade e responsabilidade. Como visto anteriormente, a crise burocrática da gestão pública brasileira originou-se no regime militar, em face do patrimonialismo que permitiu o recrutamento de gestores através das empresas do Estado. Há divergências entre o emprego pela máquina pública do Estado do sistema híbrido de administração, ou seja, entidades que fornecem serviços com apoio da arrecadação tributária, mas também com patrocínio privado. Soma-se a isto a burocracia que envolve as organizações públicas. A falta de investimentos em tecnologia prejudica o aumento da celeridade nos serviços públicos, uma vez que procedimentos online demoram $74 \%$ menos que os presenciais para serem concluídos e geram um custo menor.

Disponível em: https://www.nucleodoconhecimento.com.br/administracao/teatro-nas-instituicoespublicas 
Uma breve analogia entre o teatro, seus personagens e as instituições públicas. As organizações públicas são peças sem roteiro definido, uma vez que as políticas instauradas modificam a sua atuação. Em busca do público, os atores tentam fazer o seu melhor, mas são impedidos por questões de infraestrutura, já que o aumento da celeridade no funcionalismo confronta-se com a burocracia que atrapalha os usuários. Por outro lado, o diretor vê-se de mãos atadas uma vez que deve se curvar aos patrocinadores. A ineficiência gerencial também é uma consequência das políticas instauradas pelo Estado e todos os trâmites que o chefe de uma instituição pública enfrenta para alcançar melhores condições de trabalho ou receita.

O mais importante é que esta peça deve ser mantida em cartaz, com roteiro definido, bons e eficientes atores, com patrocínio constante e espectadores satisfeitos, independente da época.

\section{REFERÊNCIAS}

ADMIN. Fundações Públicas e Privadas: Equiparação: Inconstitucionalidade. 2008. Disponível em:< http://www.altosestudos.com.br/?p=41230>. Acesso em: 06 dez 2019.

ALMEIDA, G; VIEIRA, T. Três tragédias gregas: Antígona, Prometeu prisioneiro e Ájax. São Paulo: Perspectiva. 1997

ANDRADE, Regis de Castro. Estrutura e organização do Poder Executivo frente à opção pelo sistema de governo: Estrutura da Administração Pública e gestão de recursos humanos em quatro países parlamentaristas da Europa: França, GrãBretanha, Espanha e Itália. São Paulo: Cedec, 1993.

ANDRADE, Regis de Castro; JACCOUD, L. Estrutura e organização do poder Executivo. Brasília: ENAP/SAF, vol. I. 1993

ARAGÃO, Cecilia Vescovi de. Burocracia, eficiência e modelos de gestão pública: um ensaio. 1997.

Disponível em:< 
http://www.bresserpereira.org.br/Documents/MARE/Terceiros-Papers/97Arag\%C3\%A3o,CVescovide48(3).pdf>. Acesso em: 06 dez 2019.

BARTHES, R. O teatro grego. In. O óbvio e o obtuso - ensaios críticos III. Trad. Léa Novaes. Rio de Janeiro: Nova Fronteira. 1990

BEZERRA, Marcos Otávio. Corrupção: um estudo sobre poder público e relações pessoais no Brasil. Rio de Janeiro: Relume Dumará, 1995.

BID (Banco Interamericano de Desenvolvimento) e OCDE (Organização para a Cooperação e Desenvolvimento Econômico). 2016. Government at a Glance 2017. París: OCDE. Disponível em: http://dx.doi.org/10.1787/gov_glance-2017-en.. Acesso em: 06 dez 2019

BOBBIO, Norberto. A era dos direitos. Rio de Janeiro: Campus, 1992.

BRASIL. Constituição da República Federativa do Brasil, 1988. Disponível em: <https://www2.senado.leg.br/bdsf/bitstream/handle/id/518231/CF88_Livro_EC91_20 16.pdf >. Acesso em: 06 dez 2019.

BRASIL. Decreto lei 200/67. Disponível em: $<$ https://presrepublica.jusbrasil.com.br/legislacao/104099/decreto-lei-200-67>. Acesso em: 06 dez 2019.

BRASIL. Plano Diretor da Reforma do Aparelho do Estado. Brasília: 1995. Disponível em:< $\quad$ http://www.biblioteca.presidencia.gov.br/publicacoesoficiais/catalogo/fhc/plano-diretor-da-reforma-do-aparelho-do-estado-1995.pdf >. Acesso em: 06 dez 2019.

BRASIL. Burocracia e Politicas Públicas no Brasil: interseções analíticas. Brasília, $2018 . \quad$ Disponível em: <http://repositorio.enap.gov.br/bitstream/1/3247/1/livro_Burocracia\%20e\%20pol\%C3 \%ADticas\%20p\%C3\%BAblicas\%20no\%20Brasil\%20- 
\%20interse\%C3\%A7\%C3\%B5es\%20anal\%C3\%ADticas.pdf>. Acesso em: $06 \mathrm{dez}$ 2019.

BRASIL. Jurisdrama. Disponível em:<http://www.jurisdrama.ufrj.br/>. Acesso em: 06 dez 2019.

CALEGARI, Luiza. Percepção de corrupção no Brasil é a pior em cinco anos. Revista Exame. Disponível em: < https://exame.abril.com.br/brasil/percepcao-decorrupcao-no-brasil-e-a-pior-em-cinco-anos/> Acesso em 06 dez. 2018.

CARVALHO FILHO, José dos Santos. Manual de Direito Administrativo. Rio de Janeiro: Lumen Juris $21^{\circ}$ ed. 2009

CARVALHO, Virginia Donizete de; OLIVEIRA, Thais Aluxe de; SILVA, Daniele Cristhiane da. Valores organizacionais em instituições públicas brasileiras: percepções dos servidores em diferentes posições hierárquicas e tipos de entidade da administração indireta. 2013. Disponível em:< http://www.scielo.br/pdf/ram/v14n5/04.pdf >. Acesso em: 06 dez 2019.

DE GIORGI, R. Direito, tempo e memória. Trad. Guilherme Leite Gonçalves. São Paulo: Quartier Latin, 2006.

DINIZ, Gustavo Saad. Direito das Fundações Privadas - Teoria Geral e Exercício das Atividades Econômicas. 2. ed. Porto Alegre: Síntese, 2003.

FERLIE, Ewan; ASBURNER, Lynn; FITZGERALD, Louise; PETTINGREW, Andrew. A nova administração pública em ação. Trad. Sara Rejane de Freitas Oliveira. Brasília: ENAP, 1999.

FERRARI, Hamilton. Correio Braziliense. Burocracia: setor público leva 5,5 horas para realizar único procedimento 2018. Disponível em: $<$ https://www.correiobraziliense.com.br/app/noticia/economia/2018/06/11/internas_ec onomia,687669/burocracia-setor-publico-leva-5-5-horas-para-realizar-unicoprocedime.shtml>. Acesso em: 06 dez 2019. 
FINLEY, M.I. Aspectos da Antiguidade. Trad. Marcelo Cipolla. São Paulo: Martins Fontes, 1991.

JUSTEN FILHO, Marçal. Curso de Direito Administrativo. São Paulo: Saraiva, 2008.

LAHÓZ, André. Liberem o Crescimento. Revista EXAME, São Paulo, № 23, ano 37, ed. 805, 2003.

LIMA, Luís. Tempo perdido com burocracia custa mais ao Brasil que impostos, diz diretora do Banco Mundial. 2017. Disponível em: $<$ https://epoca.globo.com/economia/noticia/2017/09/custo-do-tempo-pesa-mais-queo-financeiro-diz-diretora-do-banco-mundial-sobre-burocracia-brasileira.html>. Acesso em: 06 dez 2019.

LOPES, J.R. Lima 0 direito na história: lições introdutórias. São Paulo: Max Limonad. 2000

MARINI, Caio. Gestão Pública: O Debate Contemporâneo. Cadernos da Fundação Luís Eduardo Magalhães. № 07. Salvador: Fundação Luís Eduardo Magalhães, 2003.

MAZILLI, Johnny. Revista Planeta. O que é que a Coreia tem? 2011. Disponível em: $<$ https://www.revistaplaneta.com.br/o-que-e-que-coreia-tem/>. Acesso em: $06 \mathrm{dez}$ 2019.

MENDONÇA, Saulo Bichara. Quimera da eficiência no serviço público desestruturado. 2017.

Disponível

em:< https://professorsaulo.jusbrasil.com.br/artigos/457823003/quimera-da-eficiencia-noservico-publico-desestruturado?ref=topic_feed >. Acesso em: 06 dez 2019.

MONTEIRO, Carolina. Correio de Uberlândia. Teatro ajuda futuros juristas na formação e cumpre papel social. 2018. Disponível em: 


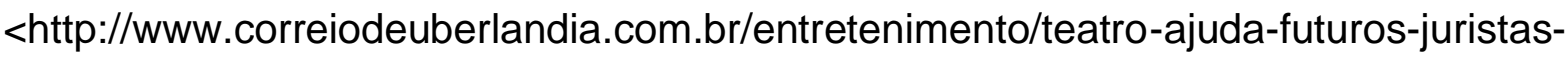
na-formacao-e-cumpre-papel-social/>. Acesso em: 06 dez 2019.

MOTTA, P. R. A modernização da administração pública brasileira nos últimos 40 anos. Revista de Administração Pública, v. 41, n. esp., p. 87-96, 2007.

MOTTA, F. C. P.; VASCONCELOS, I. F. G. Teoria geral da administração. 3. ed. São Paulo: Thomson Learning, 2006.

OLIVEIRA. Nielmar de. Agência Brasil. IBGE: taxa de analfabetismo cai 0,2 ponto $\begin{array}{lllll}\text { percentual em 2017. } & 2018 . & \text { Disponível }\end{array}$ $<$ http://agenciabrasil.ebc.com.br/economia/noticia/2018-05/ibge-taxa-deanalfabetismo-no-pais-cai-02-ponto-percentual-em-2017>. Acesso em: 06 dez 2019.

OSBORNE, David; GAEBLER, Ted. Reinventando o Governo. Tradução Sérgio Bath e Ewandro Magalhães Júnior. Brasília: MH Comunicação, 1994.

PINHO, Antônio. Evolução do Estado Moderno. In: MACHADO, Geraldo et al. Gestão Pública: Desafios e Perspectivas. Cadernos da Fundação Luís Eduardo Magalhães. n 01. Salvador: Fundação Luís Eduardo Magalhães, 2001.

PEREIRA, Luiz Carlos Bresser. Da administração Pública burocrática à gerencial. Revista do Serviço Público: ENAP, ano 47, v. 120, 1996.

PEREIRA, Luiz Carlos; SPINK, P.K (Orgs.) Reforma do Estado e Administração Pública Gerencial. Ed. Rio de Janeiro: Fundação Getúlio Vargas, 1998.

PEREIRA, Luiz Carlos; SPINK, P. Reforma do Estado e Administração Pública Gerencial. 3. Ed. Rio de Janeiro: Fundação Getúlio Vargas, 1999.

PORTAL EDUCAÇÃO. A História do Teatro no Brasil e no mundo. Disponível em: $<$ https://www.portaleducacao.com.br/conteudo/artigos/direito/historia-do-teatro-nobrasil-e-no-mundo/50069>. Acesso em: 06 dez 2019. 
RAYOL, Paulo André Araújo. Fundações públicas e privadas. 2017. Disponível em: $<$ https://jus.com.br/artigos/59258/fundacoes-publicas-e-privadas >. Acesso em: 06 dez 2019.

REALE, Miguel. Filosofia do Direito. 20. Ed. São Paulo: Saraiva. 2009

RIZZO, Sérgio. Crítica: A Repartição do tempo. 2018. Disponível em: $<$ https://oglobo.globo.com/rioshow/critica-reparticao-do-tempo22349905\#ixzz5PfxLOq4X>. Acesso em: 06 dez 2019.

ROESLER, Átila da Rold Justificando. As instituições Públicas não estão funcionando. Disponível em: < http://justificando.cartacapital.com.br/2017/12/13/asinstituicoes-publicas-nao-estao-funcionando/ > Acesso em: 06 dez 2019.

ROSENFIELD, K.H. Introdução, Comentários e notas. In: Sófocles. Antígona. Trad. Lawrence Flores Pereira. Rio de Janeiro: Topbooks. 2006

SCHAUN, Raimundo. Comunicação, Poder e Democracia. São Paulo: IPCJE, 1986.

SEGAL, C. O ouvinte e o espectador. In: Vernant, J-P. (org.). O homem grego. Trad. Maria Jorge Vilar de Figueiredo. Lisboa: Editorial Presença. 1994

SENADO. Jus Brasil. Ana Amélia defende fortalecimento de instituições públicas. 2013. Disponível em:< https://senado.jusbrasil.com.br/noticias/100486565/anaamelia-defende-fortalecimento-de-instituicoes-publicas>. Acesso em: 06 dez 2019.

SILVA, Camila Garcia da. Revista Liberdades. $O$ caso dos Irmãos Naves. Disponível em:

$<$ http://www.revistaliberdades.org.br/site/outrasEdicoes/outrasEdicoesExibir.php?rco n_id=58>. Acesso em: $06 \mathrm{dez} 2019$.

SILVA, L. P.; FADUL. A produção científica sobre cultura organizacional em organizações públicas no período de 1997 a 2007: um convite à reflexão. Revista de Administração Contemporânea, v. 14, n. 4, art. 5, p. 651-669, 2010. 
SODRÉ, Nelson W. Síntese de história da cultura brasileira. $18^{\circ} \mathrm{ed}$. Rio de Janeiro: Bertrand Brasil, 1996.

STUKART, Herbert L. Ética e Corrupção nas Empresas com Enfoque sobre Compras. Salvador: ABAM - Associação Brasileira de Administração de Material. Caderno de Administração de Materiais. № 05, 1988.

SUPREMO TRIBUNAL FEDERAL. ADI 191-4. Relatora Ministra Carmen Lúcia. Disponível< file:///C:/Users/CLIENTE/Downloads/STF\%20\%20ADI\%20n\%C2\%BA\%20191\%20RS\%20(2).pdf > Acesso em.: 06 dez 2019.

TEIXEIRA, Glória. Direito e Estudos Teatrais. In: Teatro do Mundo. Universidade do Porto. 2018. Disponível em: <http://ler.letras.up.pt/uploads/ficheiros/10182.pdf> Acesso em: 06 dez 2019.

VERNANT, J-P e VIDAL-NAQUET, P. Mito e tragédia na Grécia antiga I e II. Vv. trad. São Paulo: Perspectiva. 1999

Enviado: Novembro, 2019.

Aprovado: Janeiro, 2020. 